\title{
A STUDY OF THE ENERGY CONTENT OF THE SEISMIC WAVES P AND pP*
}

\author{
By H. M. Mooney
}

\begin{abstract}
THE energy observed in the seismic waves $\mathrm{P}$ and $\mathrm{pP}$ in a large number of earthquakes is compared, by means of two partly independent methods, with the theoretical energy calculated from a standard equation. The results are analyzed, depth of focus, distance from epicenter to observing station, geographical loeation of epicenter, and azimuth from station being used as variables. When compared with the theoretical ratio, the ratio of the energy in $\mathrm{pP}$ to the energy in $\mathrm{P}$ averaged over a distance range $60^{\circ}-90^{\circ}$ is observed to decrease with depth, by 0.5 on a logarithmic scale of energy between 100 and $600 \mathrm{~km}$. depth of focus. The results for the two waves are compared separately with theoretical values, and the observed effect appears to be about equally due to an increase of $P$ energy and a decrease of $\mathrm{pP}$ energy with depth. The theoretical formula is reëxamined to determine if permissible changes in the assumptions or numerical values can account for the results. No such changes are found; certain assumptions with respect to increased absorption of energy near the surface of the earth provide a partial qualitative explanation, but quantitatively they eannot be reconeiled with data from other sources. The variation with distance between observed and calculated energies is not large enough to be treated quantitatively; slight changes in the slope of the accepted velocity vs. depth curve are tentatively suggested on the basis of it. The energy ratio $\mathrm{pP} / \mathrm{P}$ compared to the theoretical ratio is significantly too large in shallow earthquakes occurring in the Aleutian region and can be attributed to $\mathrm{pP}$ rather than P. For shallow shocks in the New Hebrides region and very deep shocks of the Southwest Pacific there is some indication that the energy ratio is smaller than for comparable shocks elsewhere. Data on observed wave periods are given. The effect of differences between instruments is considered.
\end{abstract}

The PURPose of this work is to study the relative energy observed in $\mathrm{P}$ and $\mathrm{pP}$ and, if possible, to draw conclusions concerning the internal constitution of the earth. For this purpose, energy in $\mathrm{P}$ and $\mathrm{pP}$ (as well as PP for a restricted distance range) is calculated from the amplitudes and period observed on a large number of seismograms. This is compared with the expected energy, computed from a standard formula.

As an alternative to computing separately the expected energies for the individual waves, the differences between expected and observed results for $P$ may be attributed completely to the former, to provide corrected theoretical values. If spherical symmetry of the earth be assumed, the energy expected in $\mathrm{pP}$ at a particular distance between epicenter and observing station is the same as the energy in $\mathrm{P}$ for a (calculable) slightly shorter distance, subject to a correction for the additional path to the surface and back to hypocentral depth. In this way theoretical energies for $\mathrm{pP}$ are determined. The difference between these and observed energies can be attributed to the additional $\mathrm{pP}$ path or to conditions at the hypocenter, but, subject to the assumptions, not to the path common to $\mathrm{P}$ and $\mathrm{pP}$.

* Manuscript received for publication January 7, 1950. 


\section{Materials}

The nature of the problem restricts useful data to earthquakes originating at depths greater than $50 \mathrm{~km}$. and distant $20^{\circ}-103^{\circ}$ from the observing station. Seismograms used in this work were recorded at Pasadena (a few at Mount Wilson) between 1935 and 1945. Amplitudes and periods for the selected phases were read from 407 seismograms representing 269 earthquakes. These readings have been selected from a larger body of data as least likely to introduce errors arising from wrong identification of phases and from uncertainties due to wave form.

The instruments which provided data useful for this purpose are of the Benioff variable-reluctance type, one vertical and two horizontal components with pendulum period 1 second and damping constant 0.8. Each instrument records by means of both a short period ( $0.2 \mathrm{sec}$.) and a long period (90 sec.) galvanometer. Torsion instruments $(6$ sec. period) provided a few readings. After resolving horizontal components into single readings, the distribution of readings is: short-period vertical, 65 per cent; long-period vertical, 20 per cent; short-period horizontal, 8 per cent; long-period horizontal (including torsion), 7 per cent. Amplification-vs.-input-period curves for the various instruments, necessary to determine ground amplitudes, are on file at the Seismological Laboratory in Pasadena. It should be noted that in two cases the relative amplification (shown by the shape of the curve) is much more important than absolute amplification, which is less accurately known: first, when amplitude ratio of two phases from the same seismogram is considered; second, when the expected energy of $\mathrm{pP}$ is calculated from the observed energy of $\mathrm{P}$, as described above.

\section{THEORY}

The theory necessary for computing the expected energy in seismic waves as a function of distance between source and observing station, hypocentral depth, wave type, and wave path has been treated by several authors. The form most convenient for the present purpose has been given by Gutenberg. ${ }^{1}$ He introduces a parameter $A$ which can be calculated both theoretically ( $A$ theoretical, or $A_{\mathrm{t}}$ ) and from observations ( $A$ observed, or $A_{\mathrm{o}}$ ).

$$
\begin{aligned}
\text { Theoretical } A: A_{\mathrm{t}} & =C-\log \frac{1}{K \vee \overline{E_{1}}}\left(\frac{u, w}{T}\right)_{\text {theoretical }} \\
\text { Observed } A: A_{o} & =M-\log \left(\frac{u, w}{T}\right)_{\text {ouserved }}-0.1(M-7)
\end{aligned}
$$

${ }^{1}$ B. Gutenberg, "Theorie der Erdbebenwellen," Handbuch der Geophysik, Vol. 4 (1932); idem, "Energy Ratio of Reflected and Refracted Seismic Waves," Bull. Seism. Soc. Am., 34: 85102 (1944); "Magnitude Determination for Deep-Focus Earthquakes," ibid., 35: 117-130 (1945); and particularly, idem, "Amplitudes of P, PP, and S and Magnitude of Shallow Earthquakes," ibid., 35: 57-69' (1945). 
where $C$ is a constant assumed characteristic of waves starting as a particular type; $K$ is the fraction of the energy $E_{1}$ going into a particular type of wave; $M$ is the magnitude of the shock $(10) ; u, w$ are ground amplitudes (horizontal, vertical) at the observing station; $T$ is the wave period. These derivations are carried through by Gutenberg. ${ }^{2}$ They involve:

1) The statement that energy is proportional to the square of the ratio, amplitude divided by period;

2) the definition of magnitude and its empirical relation to energy (10);

3 ) the assumption that duration of a phase increases with distance at the same rate as the period increases; and

4) the assumption that $C$ has the same value for all waves starting as, say, $P$.

Gutenberg $^{3}$ has determined a value of $C=6.3$ for $\mathrm{P}$, which includes $\mathrm{pP}$ and $\mathrm{PP}$ as well. This value will be used for convenience, although in the method of calculating $A$ for $\mathrm{pP}$ from $A$ for $\mathrm{P}$ only the difference, if any, between $C_{\mathrm{P}}$ and $C_{\mathrm{p}} \mathrm{p}$ affects the results.

The theoretical ground displacement at the observing station is given ${ }^{4}$ by

$$
u, w=Q_{\mathrm{H}, \mathrm{z}} K T \sqrt{E_{1}} \sqrt{\left(F_{1} F_{2} \cdots\right) e^{-k D} \frac{\sin i_{h} d i_{h} / d \Delta}{\sin \Delta \cos i_{0}}}
$$

where, in addition to the quantities defined above, $Q$ is the ratio of ground displacement to incident amplitude; $F$ terms represent losses of energy at reflections and refractions; $D$ is path length and $k$ the absorption coefficient per unit path length; $\Delta$ is the angular distance between source and observing station; $i_{k}$ and $i_{0}$ are incident angles of the rays at the source and at the surface of the earth.

The assumptions made in deriving this equation include equal distribution of energy in all directions about the source, spherical symmetry of the earth except within the crustal layers, and all those assumptions which underlie the ray treatment of seismic waves.

\section{Calculation of Theoretrcal Quantities}

Travel-time curves provide the raw material for these calculations. For any wave, the slope of the travel-time curve at a particular point represents the apparent surface velocity, $\vec{v}_{0}$, which for a spherically symmetrical earth is sufficient to determine a characteristic ray parameter $n$,

$$
n=\frac{r o}{\vec{v}_{0}}=\frac{r \sin i}{v}
$$

For any point on the ray, $r, i$, and $v$ are radial distance from the center of the

2 "Amplitudes of P, PP, and S..."

s "Amplitudes of Surface Waves and Magnitude of Shallow Earthquakes," Bull. Seism. Soc. Am., 35: 3-12 (1945).

"Gutenberg, "Amplitudes of P, PP, and S ...," equation 2. 
earth, angle of incidence between ray and radius, and velocity. In particular, knowledge of $n$ and of the velocity distribution with depth is sufficient to calculate $i$ at the surface of the earth $\left(i_{0}\right)$, at the (roughly) $40 \mathrm{~km}$. depth discontinuity $\left(i_{40}\right)$, and at the hypocenter $\left(i_{h}\right)$. Velocities are assumed as follows:

$\begin{array}{ccc} & \text { Velocity } & \text { Depth } \\ \text { Continental structure............. } & 5.6 \mathrm{~km} / \mathrm{sec} . & 0-15 \mathrm{~km} . \\ & 6.0 & 15-40 \\ & 7.7 & 40+ \\ \text { Pacific structure............... } & 8.0 & 0\end{array}$

and for greater depths the values given by Bullen. ${ }^{5}$

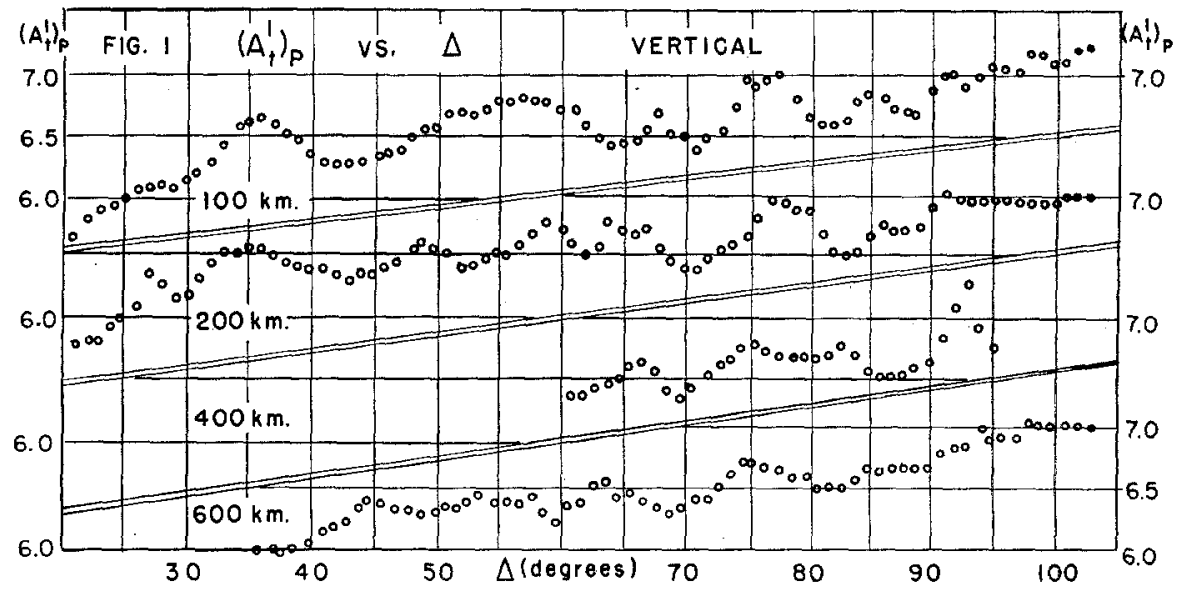

Fig. 1.

Calculations of $A_{\mathrm{t}}$ as a function of distance $\Delta$ were made for focal depths $h=100,200,400$, and $600 \mathrm{~km}$. For $\mathrm{P}$ and $\mathrm{pP}$, a $\Delta$ range $20^{\circ}-100^{\circ}$ was used; $A_{t}$ was also determined for PP for $\Delta=60^{\circ}-90^{\circ} . Q$ and $F$ terms are tabulated by Gutenberg ${ }^{6}$ as functions of Poisson's Ratio (here assumed 0.25) and angles of incidence. Fnergy losses were calculated for refraction at the $40 \mathrm{~km}$. discontinuity and reflection at the surface of the earth. In particular, the latter for $\mathrm{pP}$ is denoted by $F_{2} ; F_{1}, F_{3}$, and $F_{4}$ correspond to the three crossings of the $40 \mathrm{~km}$. break along the path of $\mathrm{pP}$, starting from the hypocenter, and $F_{5}$ to the one crossing along the path of P. $k$ has been found $d^{7}$ to be about $1.2 \times 10^{-4} / \mathrm{km}$. for body waves. $D$ is measured from a scale plot of ray paths. $d i_{h} / d \Delta$ is found by plotting $i_{\hbar}$ against $\Delta$, smoothing the resulting curves to eliminate slope reversals (impossible, considering the known velocity distribution outside the

${ }^{5}$ K. E. Bullen, Introduction to the Theory of Seismology (Cambridge University Press, 1947), p. 211.

"Gutenberg, "Energy Ratio ..."

7 Gutenberg, "Magnitude Determination..." 
core), and measuring the slopes. This is the only quantity in equation (3) which does not vary smoothly and in the same direction throughout the entire distance range for a particular depth, and the largest uncertainties are introduced by it. To reduce subjective errors, an average was taken of four separate slope measurements made on four forms of the travel-time data. The resulting theoretical quantities for the vertical component, $A_{t}$ vs. $\Delta$, are shown in figures 1 and 2 . Values for horizontal readings may be determined by using the corrections specified by Gutenberg ${ }^{8}$ for both $\mathrm{P}$ and $\mathrm{pP}$.

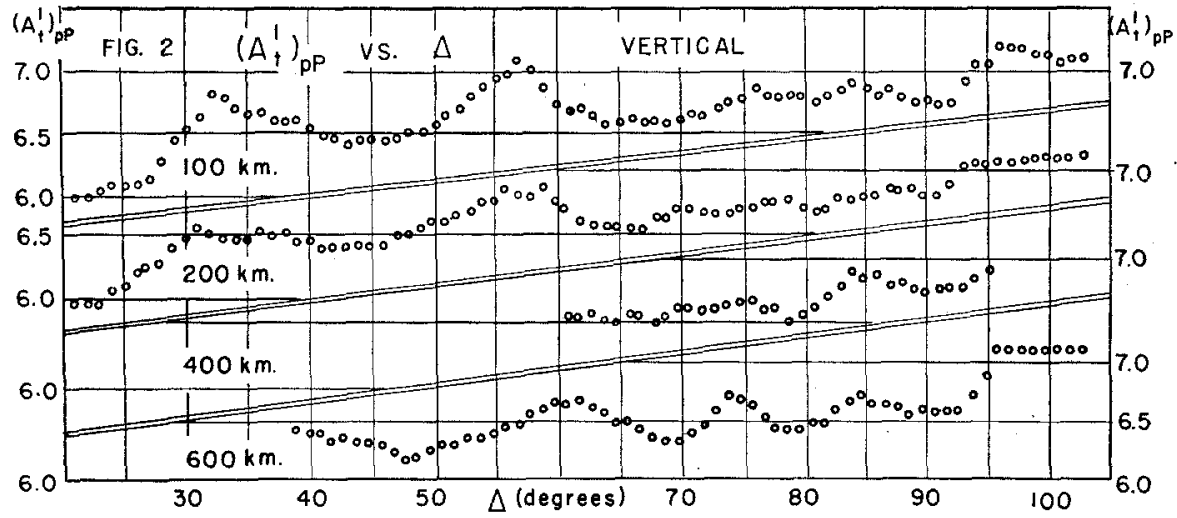

Fig. 2.

\section{Methods of Presenting Data}

The independent variables available are depth of focus $h$, distance $\Delta$ and azimuth from epicenter to observing station, and epicentral region. To study a particular one, it is necessary to keep variation in the others to a minimum. For this reason the dependent variables are plotted as a function of $\Delta$ for depth ranges $50-150,150-250,250-350,350-500$, and $500-700 \mathrm{~km}$.; the variation with depth can be studied by the use of restricted $\Delta$ intervals from these curves. Azimuthal and regional variations must be treated by an averaging process based on the original numerical results.

The dependent variables, or residuals, represent deviations of the observed amplitude/period ratios from the theoretical values, on a logarithmic scale. If the theoretical values, $A_{t}$, are those calculated directly from the travel-time curves, they may be designated $A_{\mathrm{t}}{ }^{1}$ and the residuals $\left(A_{\mathrm{t}}{ }^{1}-A_{\mathrm{o}}\right)_{\mathrm{P}},\left(A_{\mathrm{t}}{ }^{1}-A_{\mathrm{o}}\right)_{\mathrm{pP}}$, and $\left(A_{\mathrm{t}}{ }^{1}-A_{\mathrm{o}}\right)_{\mathrm{PP}}$ formed for the various waves. Positive values indicate observations larger than expected. Inspection of the definitions of $A$ shows that the difference, $\left(A_{\mathrm{t}}{ }^{1}-A_{0}\right)_{\mathrm{pP}}-\left(A_{\mathrm{t}}{ }^{1}-A_{\mathrm{o}}\right)_{\mathrm{P}}$, may be interpreted as

$$
\frac{\text { observed energy ratio } \mathrm{pP} / \mathrm{P}}{\text { expected energy ratio } \mathrm{pP} / \mathrm{P}}
$$

${ }^{8}$ Gutenberg, "Magnitude Determination ...," fig. 2. 

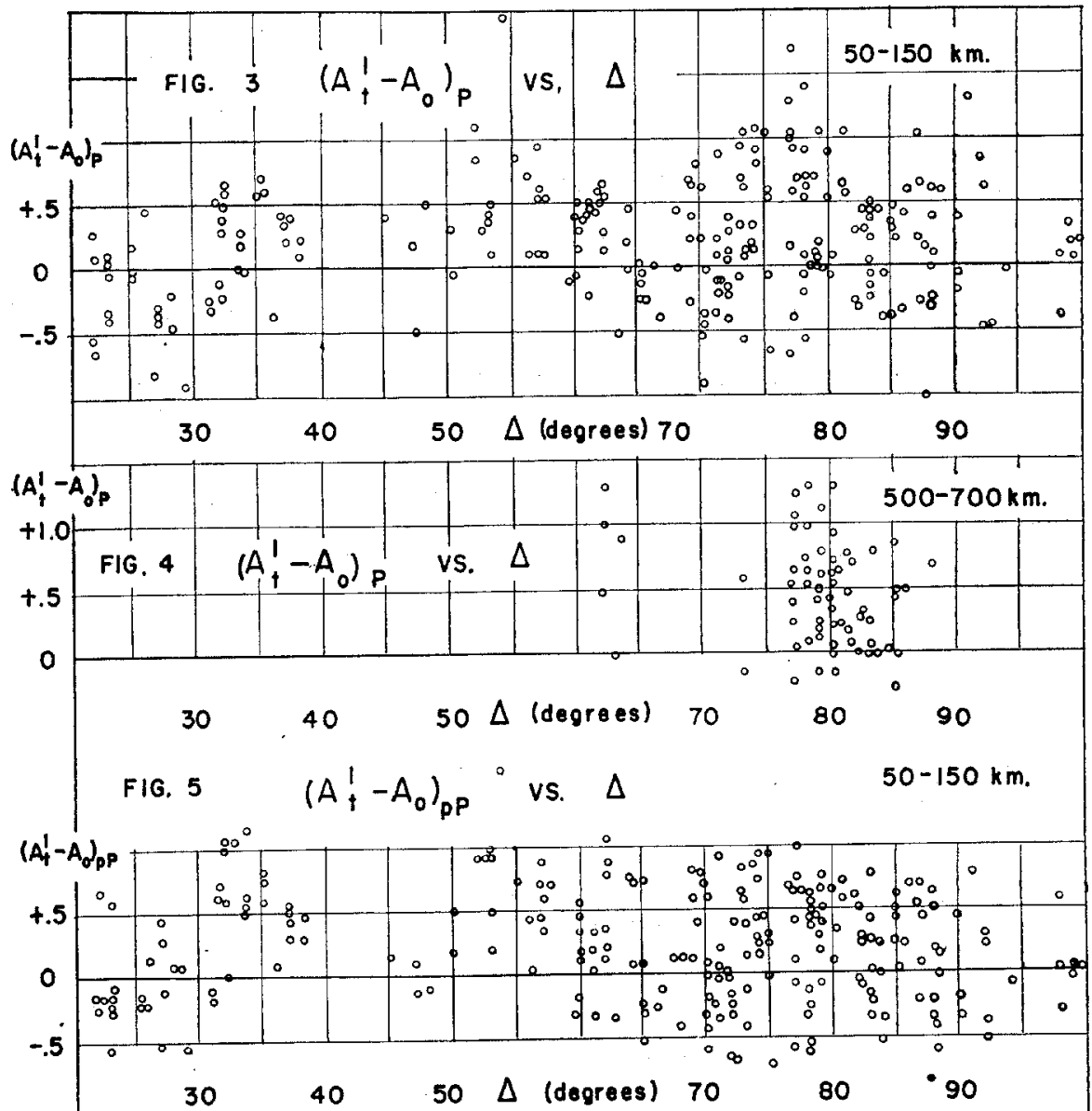

$\left(A_{1}^{2}-A_{0}\right)_{P P}$ FIG. $6 \quad\left(A_{+}^{2}-A_{0}\right)_{P P}$ vS. $\Delta \quad: \quad 50-150 \mathrm{~km}$.

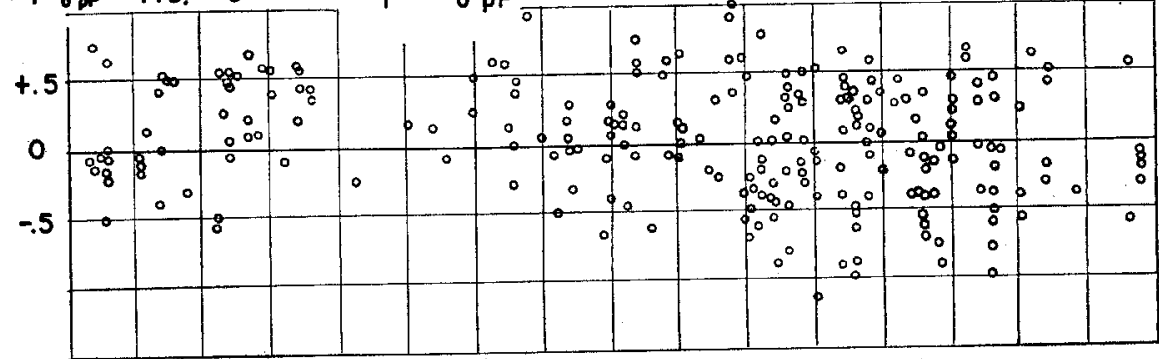

Figs. 3-6. 
on a logarithmic scale, where as noted above the energy values have been obtained from (amplitude/period) ${ }^{2}$.

An alternative residual may be formed on the assumption that the energy to be expected in $\mathrm{pP}$ at a particular distance $\Delta_{1}$ should differ from that in $\mathrm{P}$ at a slightly shorter distance $\Delta_{2}$ by only the loss of energy over the additional path characteristic of $\mathrm{pP}$. The further assumption of spherical symmetry in the earth is implied for depths greater than $50 \mathrm{~km}$. and within a distance range $\Delta_{2}-\Delta_{1}$. The latter is usually $1^{\circ}-2^{\circ}$ in this work, never more than $8^{\circ}$. To determine the desired $A_{t}$ for $\mathrm{pP}$, an average curve is drawn through the $\left(A_{t}{ }^{1}-\right.$ $\left.A_{\mathrm{o}}\right)_{\mathrm{P}}$ vs. $\Delta$ curves for the various depth ranges. For each value of $\Delta$, the ordinate for each curve is subtracted from the corresponding $\left(A_{t}{ }^{1}\right)_{\mathrm{P}}$, in effect producing a zero residual through changing the latter. This "corrected" value applies to $\mathrm{P}$ at, say, $\Delta_{2}$. The method of calculating $\Delta_{1}-\Delta_{2}$ is described by Gutenberg and Richter. ${ }^{9}$ After applying corrections for the additional pP absorption, reflections, and refractions, the final result may be designated $\left(A_{\mathrm{t}}{ }^{2}\right)_{\mathrm{pP}}$, calculated for distance $\Delta_{1}$ and a particular depth. The residual $\left(A_{\mathrm{t}}{ }^{2}-A_{\mathrm{o}}\right)_{\mathrm{pP}}$ can be shown to permit the same physical interpretation as $\left(A_{\mathrm{t}}{ }^{1}-A_{0}\right)_{\mathrm{p}}-\left(A_{\mathrm{t}}{ }^{1}-A_{\mathrm{o}}\right)_{\mathrm{P}}$ in the last paragraph.

This residual has certain advantages: (1) Errors in absolute amplification curves for the instruments tend to be eliminated. (2) Subject to the assumptions, the residuals can be attributed to a particular portion of the path of $\mathrm{pP}$ or else to differences between $\mathrm{pP}$ and $\mathrm{P}$ energies leaving the hypocenter. (3) Subjective errors introduced in determining the graphical second derivative of travel-time curves to find $A_{\mathrm{t}}{ }^{1}$ are minimized, because the same determination can be used for both $\mathrm{P}$ and $\mathrm{pP}$. (4) It may be compared with $\left(A_{\mathrm{t}}{ }^{1}-A_{\mathrm{o}}\right)_{\mathrm{pP}}-$ $\left(A_{\mathrm{t}}{ }^{1}-A_{\mathrm{o}}\right)_{\mathrm{P}}$ to provide a partly independent check on a physically interpretable quantity. (5) The absolute value of the constant $C$, equation 1 , does not need to be known.

Figures 3-6 are typical of the results obtained by plotting the various residuals against $\Delta$.

\section{EFFECT OF Instruments}

Numerical values of the various residuals should be independent of the instrument from which they are determined. To investigate this point, the shortperiod horizontal and the long-period vertical instruments were separately checked against the short-period vertical, by forming the numerical difference between these residuals for all earthquakes which provided useful readings on more than one instrument. In effect, the quantity determined for each earthquake was

$\left(A_{o}\right)$

short-period horizontal or long-period vertical instrument
$-\left(A_{0}\right)$

short-period vertical instrument

\footnotetext{
9 B. Gutenberg and C. F. Richter, "Materials for the Study of Deep-Focus Earthquakes" (second paper), Bull. Seism. Soc. Am., 27: 157-183 (1937).
} 
It will be noted that positive values of this quantity indicate greater energy observed on the short-period vertical instrument than on the instrument with which it is being compared. No significant variation with distance is indicated

TABLE 1

Numerical Values of Residuals

\begin{tabular}{|c|c|c|c|}
\hline Depth range & $P$ & $\mathrm{pP}$ & No. of readings \\
\hline \multicolumn{4}{|c|}{ Short-period vertical vs. long-period vertical instruments } \\
\hline $50-150 \mathrm{~km}$ & +0.30 & +0.37 & 42 \\
\hline $500-700 \ldots$ & +0.60 & +0.47 & 13 \\
\hline
\end{tabular}

Short-period vertical vs. short-period horizontal instruments

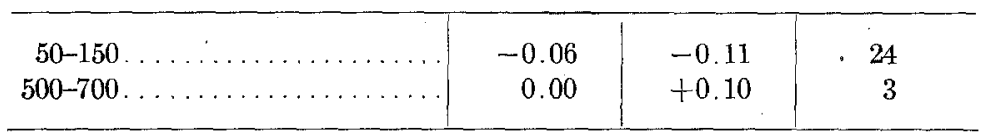

TABLE 2

Median Values of Peiriod Ratios

(Number of readings in parentheses)

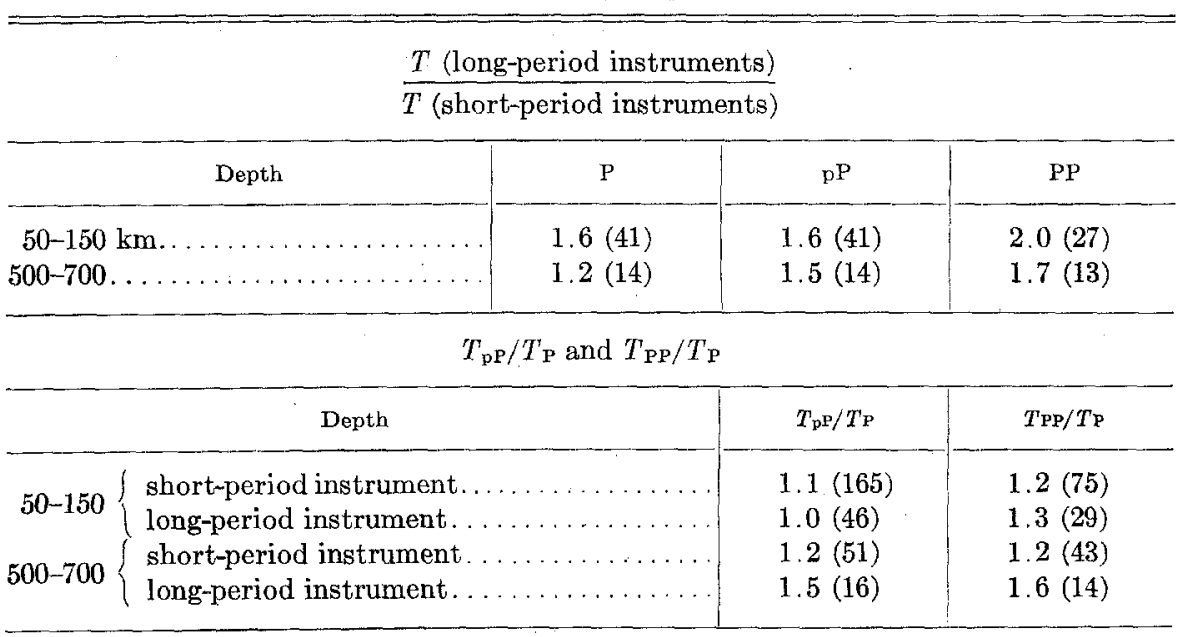

on the resulting plots against distance. Summarizing for the extreme depth ranges, the results averaged over the entire distance range, $20^{\circ}-100^{\circ}$, are shown in table 1.

Since the probable error of residuals in this work is 0.3 , it may be concluded that (1) no significant discrepancy occurs between horizontal and vertical 
short-period instruments, (2) the short-period vertical instrument indicates consistently more energy in the same wave than the long-period vertical, and (3) the analysis of variation with depth must take into account differences between long- and short-period vertical instruments, but the analysis of variation with distance need not do so.

The discrepancy (point 2, just above) is probably partly due to the actual selection of different components from a complex wave by the two instruments, and partly to instrumental differences.

\section{Data on Wave Periods}

Table 2 provides data on observed wave periods, in the form of median values taken from plots of the tabulated quantities against distance. Considering the scatter of the data, it is doubtful that much significance can be attached to quantitative treatment. ( $\mathrm{PP}$ values apply only to the distance range $60^{\circ}-90^{\circ}$, the others to $20^{\circ}-100^{\circ}$ ).

\section{RESULTS}

\section{VARIATION OF ENERGY WITH DEPTH OF FOCUS}

The distance range $60^{\circ}-90^{\circ}$ includes nearly all earthquakes with focal depth greater than $200 \mathrm{~km}$. which were used in this work. The discussion of variation with depth will therefore apply to this range only. For each depth range the various types of residuals were averaged and the average value plotted as a function of depth at the midpoint of the depth range. Figure 7 shows the results.

It is concluded above that instrumental differences must be taken into account in studying variation with depth. For this reason, figures 8 and 9 show the same quantities as determined from the short- and long-period vertical instruments individually.

Two conclusions seem indicated by figures 7-9: (1) The observed energy ratio $\mathrm{pP} / \mathrm{P}$, when compared with the theoretical ratio, decreases systematically with depth by about 0.5 units (logarithmic scale) between 100 and $600 \mathrm{~km}$. This is shown by the curve for $\left(A_{\mathrm{t}}^{1}-A_{\mathrm{o}}\right)_{\mathrm{pP}}-\left(A_{\mathrm{t}}{ }^{1}-A_{\mathrm{o}}\right)_{\mathrm{P}}$. (2) The curve for $\mathrm{PP}$ roughly parallels the curve for $\mathrm{P}$ at a level lower by 0.4 unit.

The further conclusion may be drawn from figure 7 that the two methods of calculating the quantity

$$
\log \frac{\text { observed energy ratio } \mathrm{pP} / \mathrm{P}}{\text { expected energy ratio } \mathrm{pP} / \mathrm{P}}
$$

yield consistent results. This can be seen by comparing the lowest curve with the associated $x$ 's.

What physically acceptable changes can be made in the theoretical equations 


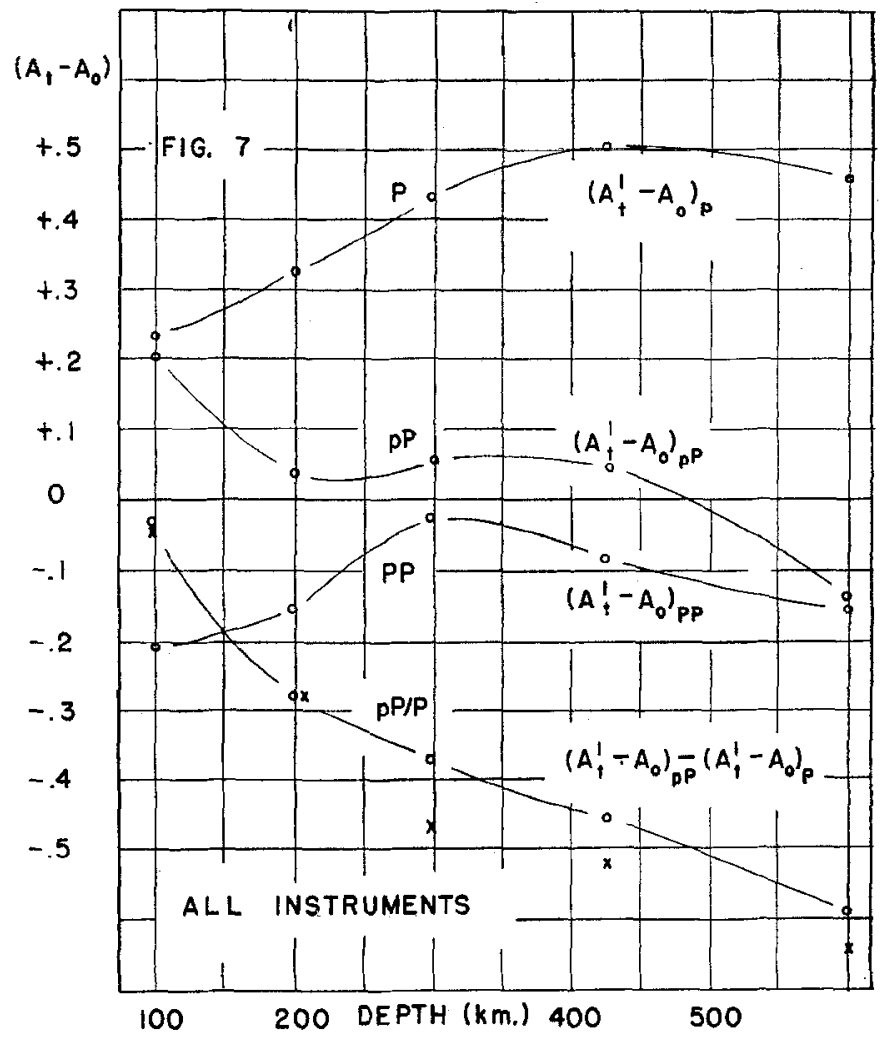

AVERAGED RESIDUALS vs. DEPTH

$$
\begin{gathered}
\Delta=60^{\circ}-90^{\circ} \\
\left(x:\left(A_{+}^{2}-A_{0}\right)_{p P} \text { for comparison }\right)
\end{gathered}
$$

Fig. 7. 


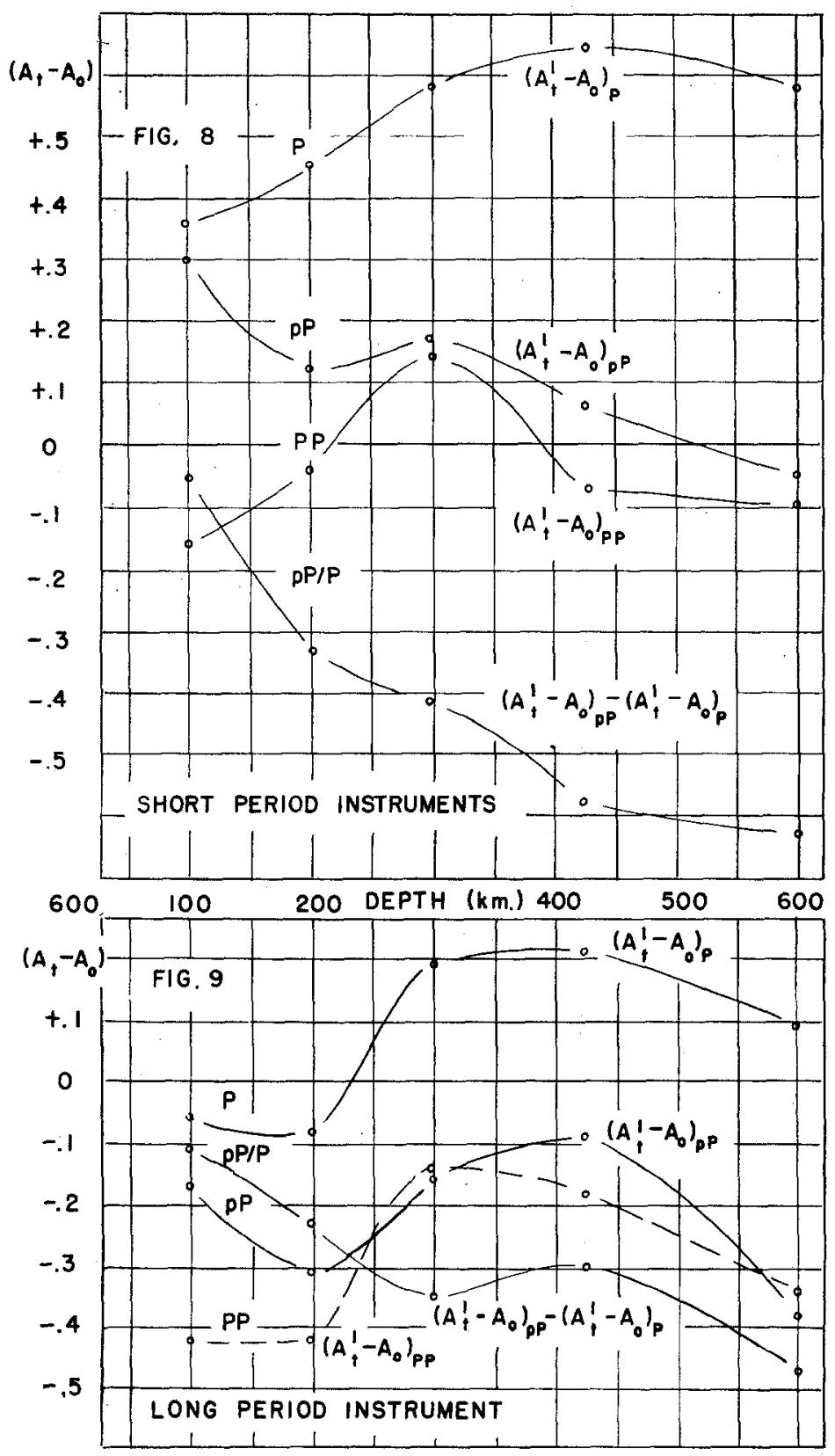

Figs. 8 and 9. 
$(1,2,3)$ to eliminate the variation with depth? For any wave, these equations can be combined to give

$A_{\mathrm{t}}{ }^{1}-A_{\mathrm{o}}=C-\log Q \sqrt{\left(F_{1} F_{2} \cdots\right) e^{-k D} \frac{\sin i_{h} d i_{h} / d \Delta}{\sin \Delta \cdot \cos i_{0}}}-M+\log \left(\frac{u, w}{T}\right)_{\text {observed }}$

The possible effect of each term of this equation has been considered. Some, such as the constant $C$ and $d i_{h} / d \Delta$, can be eliminated because the uncertainty introduced by them is not expected to vary with depth. Others, such as the conversion factor $Q$, the trigonometric terms, and the refraction losses at the Mohorovičić discontinuity $\left(F_{1} F_{3} F_{4} F_{5}\right)$ can be shown to produce an effect at least an order of magnitude too small to explain the observed results. Still others, such as $C$ and the magnitude $M$, are eliminated in considering the clear-cut result of conclusion 1 above, for no matter what the uncertainty in the determination of magnitude, for example, it cannot affect the energy ratio $\mathrm{pP} / \mathrm{P}$ for one earthquake.

Three possibilities seem promising: $F_{2}$ (pP surface reflection coefficient), $e^{-k D}$ (absorption), and the assumption of equal energy distribution about the hypocenter.

$F_{2}$ theoretically depends only on Poisson's ratio and the angle of incidence $i_{0}$ at the surface of the earth; no physically permissible change in the former can affect the results. The latter depends on the surface velocity, here taken 5.6 $\mathrm{km} / \mathrm{sec}$. in continental regions, but an error in this velocity will only indirectly affect the variation with depth. The original calculations gave $i_{0}=17^{\circ}$ and $18^{\circ}$ at 100 and $600 \mathrm{~km}$., respectively. The observed result of conclusion 1 can be accounted for if $\sqrt{F_{2}}$ at $600 \mathrm{~km}$. has a value $3 / 10$ that at $100 \mathrm{~km}$. According to Gutenberg, ${ }^{10}$ this requires the improbable value $i_{0}=46^{\circ}$ at $600 \mathrm{~km}$.

The reflection and refraction coefficients were calculated by Gutenberg ${ }^{11}$ on the assumption of a surface layer several times greater than a wave length. Since the wave lengths considered here are of the order of $5-10 \mathrm{~km}$., this condition may not be satisfied and the actual loss of energy at the surface may be greater than calculated. Such loss should not produce a large depth effect, however.

In terms of absorption, several observed effects can be accounted for qualitatively by assuming a layer several hundred kilometers thick near the surface of the earth, with an unusually high absorption coefficient. As the depth of focus increases, waves starting downward from the hypocenter, such as $\mathrm{P}$ and $\mathrm{PP}$, would pass through progressively less of the hypothesized layer; the observed energy should increase with depth, roughly in the same manner for $\mathrm{PP}$ as for $\mathrm{P}$. Waves starting upward such as $\mathrm{pP}$, however, would travel a greater distance within the layer as the depth of focus increases; the observed

10 "Amplitudes of P, PP, and S..."

11 "Energy Ratio..." 
energy in $\mathrm{pP}$ and, even more markedly, the energy ratio $\mathrm{pP} / \mathrm{P}$, should decrease with depth. All these predicted results are observed.

Quantitative considerations rule out this possibility, however. If the uppermost $400 \mathrm{~km}$. of the earth, for example, is assumed to be characterized by an absorption coefficient $k^{\prime}$, to be determined, then the result stated in conclusion 1 above will be accounted for if $k^{\prime}=30 \times 10^{-4} / \mathrm{km}$. Compared with a value $k=1.2 \times 10^{-4} / \mathrm{km}$. for body waves determined by Gutenberg, ${ }^{12}$ this is considered much too large to be possible. To illustrate the implications, waves arriving at any distance up to $\Delta=16^{\circ}$. would be reduced in amplitude by a factor $1 / 2$ every $400 \mathrm{~km}$. of path length, a result inconsistent with local earthquake observations.

Alternatively, let it be assumed that within the mantle of the earth absorption decreases slowly with depth. Since the path of PP is closer to the surface than the path of $\mathrm{P}$ at the same distance (deepest points on the rays for $\Delta=80^{\circ}$ are roughly 1,000 and $2,500 \mathrm{~km}$.), an attenuation of $P P$ relative to $P$ would be expected. Calculations indicate that conclusion 2 above may be accounted for if the average absorption coefficient along the path is $1.2 \times 10^{-4} / \mathrm{km}$. for $\mathrm{P}$ (as originally assumed) and $3.1 \times 10^{-4} / \mathrm{km}$. for PP. Some support is given this hypothesis by a predicted and partly observed distance effect.

Several variants on the assumption of equal distribution of energy about the source have been considered. The evidence for each is either insufficient or conflicting.

\section{VARIATION OF RESIDUALS WITH DISTANCE}

Figures 3-6 are typical of the results obtained. No clear trends are evident and it is not felt that quantitative treatment is justified. The residuals $\left(A_{\mathrm{t}}{ }^{1}-A_{\mathrm{o}}\right)_{\mathrm{P}}$ may be used to suggest slight changes in the slope of $\mathrm{P}$ velocity-vs.depth data currently in use. Any tendency toward larger observed energy (more positive residuals) at a particular distance may be taken to indicate greater increase of wave velocity with depth than is assumed for the deepest point on the ray, since such an increase in velocity results in an effective concentration of energy. After all curves for $\left(A_{t}{ }^{1}-A_{\mathrm{o}}\right)_{\mathrm{P}}$-vs.-distance have been reduced to an equivalent common focal depth, the following tendencies are found to be common to most or all.

\begin{tabular}{|c|c|c|c|}
\hline Range & & $\begin{array}{l}\text { Deepest point } \\
\text { on ray }\end{array}$ & Slope should be \\
\hline $26^{\circ}-32^{\circ}$ & Negative residuals & $680-840 \mathrm{~km}$ & Decreased \\
\hline $33^{\circ}-40^{\circ}$ & Positive residuals. & $880-950$ & Increased \\
\hline $72^{\circ}-81^{\circ}$ & Positive residuals. & $2040-2400$ & Increased \\
\hline 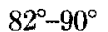 & Negative residuals & $2440-2640$ & Decreased \\
\hline
\end{tabular}

12 "Amplitudes of $\mathrm{P}, \mathrm{PP}$, and $\mathrm{S} . . . "$ 
TABLE 3

Residuals va. Region and Azimuth

\begin{tabular}{|c|c|c|c|}
\hline Region & $\Delta$ Range & Log $\frac{\text { observed ratio } \mathrm{pP} / \mathrm{P}}{\text { expected ratio } \mathrm{pP} / \mathrm{P}}$ & $\begin{array}{l}\text { No. of } \\
\text { readings }\end{array}$ \\
\hline \multicolumn{4}{|c|}{ Shallow $(50-150 \mathrm{~km}$.$) Shocks$} \\
\hline 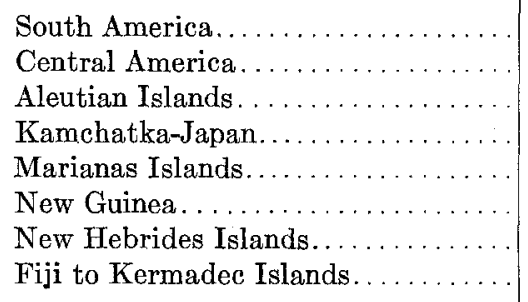 & $\begin{array}{l}52^{\circ}-85^{\circ} \\
20^{\circ}-35^{\circ} \\
30^{\circ}-50^{\circ} \\
55^{\circ}-81^{\circ} \\
83^{\circ}-92^{\circ} \\
90^{\circ}-100^{\circ} \\
81^{\circ}-88^{\circ} \\
73^{\circ}-90^{\circ}\end{array}$ & $\begin{array}{l}+0.08 \\
+0.13 \\
+0.29 \\
-0.11 \\
-0.09 \\
-0.08 \\
-0.17 \\
-0.07\end{array}$ & $\begin{array}{l}70 \\
33 \\
16 \\
45 \\
16 \\
12 \\
14 \\
15\end{array}$ \\
\hline \multicolumn{4}{|c|}{ Azimuth } \\
\hline $\begin{array}{l}\text { Mexico to South America........... } \\
\text { Aleutian Islands to Japan. .......... } \\
\text { New Guinea to Kermadec Islands.... }\end{array}$ & $\begin{array}{l}\cdots \cdots \\
\cdots \cdots \\
\cdots \cdots\end{array}$ & $\begin{array}{r}+0.09 \\
0.00 \\
-0.10\end{array}$ & $\begin{array}{r}106 \\
61 \\
41\end{array}$ \\
\hline
\end{tabular}

DeEP $(500-700 \mathrm{~km}$.) SHOCKs

(All readings)

Manchuria-Japan.

Southwest Pacific.

South America.

\begin{tabular}{l|l} 
& \\
$63^{\circ}-86^{\circ}$ & -0.48 \\
$75^{\circ}-86^{\circ}$ & -0.68 \\
$62^{\circ}-86^{\circ}$ & -0.53 \\
\hline
\end{tabular}

\begin{tabular}{|c|r|}
$\begin{array}{c}\text { Average } \\
\text { focal depth }\end{array}$ & \\
\cline { 1 - 1 } 535 & 21 \\
580 & 39 \\
620 & 8 \\
\hline
\end{tabular}

$\left(\Delta=75^{\circ}-86^{\circ}\right.$ only $)$

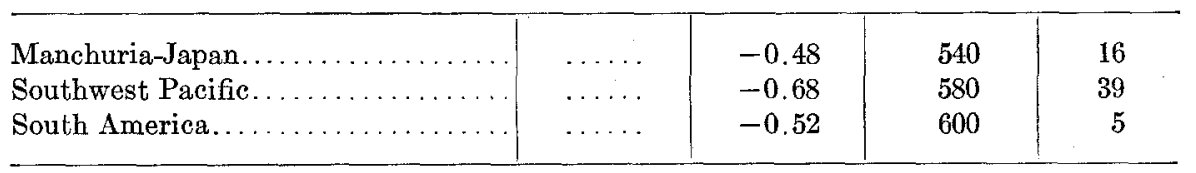

$\left(\Delta=75^{\circ}-86^{\circ}\right.$ and depth $=550-580 \mathrm{~km}$. only $)$

\begin{tabular}{l|l|l|l|r}
\hline Manchuria (Vladivostok area)........ & $\ldots \ldots$ & -0.45 & $\ldots$ & 9 \\
Southwest Pacific................... & $\ldots \ldots$ & -0.62 & $\ldots$ & 14 \\
\hline
\end{tabular}




\section{VARIATION OF RESIDUALS WITH AZIMUTH AND REGION}

Table 3 summarizes the averaged results. The quantity

$$
\log \frac{\text { observed energy ratio } \mathrm{pP} / \mathrm{P}}{\text { expected energy ratio } \mathrm{pP} / \mathrm{P}}
$$

has been selected for the dependent variable because the most clear-cut depth variation appeared in terms of it. Since it may be represented as either $\left(A_{\mathrm{t}}{ }^{2}-A_{\mathrm{o}}\right)_{\mathrm{pP}}$ or $\left(A_{\mathrm{t}}{ }^{1}-A_{\mathrm{o}}\right)_{\mathrm{pP}}-\left(A_{\mathrm{t}}{ }^{1}-A_{\mathrm{o}}\right)_{\mathrm{P}}$, the average of these quantities has been used. In most cases the difference between them is small.

As a working criterion based on a probable error of 0.3 , regional or azimuthal variations 0.3 units or greater will be termed significant, 0.2 units possibly significant. The following conclusions may be drawn:

A. Azimuthal variations in shallow shocks are too small to be significant. A tendency can be noted for residuals of southwest Pacific shocks to be slightly negative, of Central and South American shocks to be slightly positive.

B. In shallow shocks:

1) the Aleutian region produces significantly positive residuals. The effect is due to large $\mathrm{pP}$ rather than small $\mathrm{P}$ energy. Separate determinations of $\left(A_{\mathrm{t}}{ }^{1}-A_{\mathrm{o}}\right)_{\mathrm{p}},\left(A_{\mathrm{t}}{ }^{1}-A_{\mathrm{o}}\right)_{\mathrm{pF}}$ give $+0.10,+0.41$, respectively.

2) The New Hebrides region produces possibly significant negative residuals. The separation into $\mathrm{pP}$ and $\mathrm{P}$ is inconclusive.

3) South America and the Kamchatka-Japan region can be compared using the same distance range, $55^{\circ}-80^{\circ}$ approximately, as well as the same depth range. The difference, 0.2 in the direction of larger observed ratios in South America, is possibly significant.

C. In deep shocks, the residuals for the southwest Pacific region are more negative than those for other regions by a possibly significant factor. The discrepancy cannot be assigned conclusively to either $\mathrm{P}$ or $\mathrm{pP}$. The average depth data oppose the suggestion that the observed variations can be attributed to the general tendency for residuals to become more negative at greater focal depths.

The possibility of a distance effect in the Aleutian and New Hebrides regions cannot be excluded. The distance ranges for the Marianas and the New Hebrides are roughly comparable, however, and indicate less rather than more significance for the New Hebrides residuals. To the extent that the Aleutians can be compared with the same distance range in Central and South America, a real Aleutian regional effect is suggested.

Gutenberg and Richter ${ }^{13}$ have discussed these areas in terms of over-all seismicity, structure, and related characteristics. They describe a typical Pacific are, as developed for example in the Japan-Manchuria region, as follows.

\footnotetext{
${ }^{13}$ Op. cit. (see note 9 above).
} 
Starting from the Pacific basin and proceeding toward the continental mass, an oceanic deep is followed in order by regions of negative gravity anomalies and shallow earthquakes, positive gravity anomalies and slightly deeper shocks, active or recent volcanoes and shocks at about $100 \mathrm{~km}$. focal depth, older volcanism and intermediate shocks, and deep shocks. The locus of earthquake foci is sometimes interpreted as a thrust plane dipping away from the Pacific basin.

The Aleutian are differs from this pattern in that the last two features are missing, and gravity anomalies have not been studied sufficiently to determine whether they fit the pattern. The deepest shocks occur at about $170 \mathrm{~km}$. depth, and precise depths are more difficult to determine here than in most other regions.

In the New Hebrides, the normal sequence from the Pacific Basin continentward is possibly reversed. The arc is convex away from the Pacific Basin, the ocean deep lies to the southwest, and shallow shocks, volcanoes, and intermediate shocks seem to overlap or occur in reverse order. The "thrust plane" would appear to be vertical or dipping toward the Pacific Basin. A distinct break in seismic activity occurs between this region and the Fiji Islands to the east, with some suggestion of a structural offset to the south on the western side. The deepest shocks in this region occur at about $300 \mathrm{~km}$.; as in the Aleutians, depth determinations are difficult.

Comparing South America and Japan, the total seismic energy released in the two areas is not greatly different; South America, however, has larger shocks in smaller number, and the shallow shocks show a greater average focal depth.

The deep focus shocks of the southwest Pacific occur in the Tonga salient. All the features of a typical Pacific arc are developed here and the location of the andesite line is well determined. Compared with the other two regions of deep focus shocks, the surface distance between the first and the last features characteristic of the arc is smaller.

\section{SumMary of REsults}

Results will be summarized in terms of "residuals" which will represent the logarithm of the ratio, observed energy divided by theoretical energy for a particular wave.

Variation with depth.-When compared with the theoretical value, the observed energy ratio $\mathrm{pP} / \mathrm{P}$ decreases by 0.4 to 0.6 units on the logarithmic scale as the depth of focus increases from 100 to $600 \mathrm{~km}$., when averaged over the distance range $60^{\circ}$ to $90^{\circ}$. The effect appears to be due about equally to increase of $\mathrm{P}$ energy and decrease of $\mathrm{pP}$ energy with depth, although separation of data by instruments yields partly inconsistent results. The energy of PP varies with 
depth in the same manner as $\mathrm{P}$, but shows for all depths a deficiency of roughly 0.4 units.

The variation with depth of $\mathrm{pP} / \mathrm{P}$ energy ratio cannot be explained by physically permissible changes in the quantities involved in the calculation of theoretical energies. Absorption must be increased at shallow depths (say $0-400 \mathrm{~km}$.) by a factor 20 to 40 times the assumed value to account for the observed effect. This is inconsistent with other earthquake data. The observed PP energy deficiency may be accounted for by absorption twice as great along the path of $\mathrm{PP}$ as along the path of $\mathrm{P}$ for a distance range $60^{\circ}-90^{\circ}$, which corresponds to maximum ray depths of about 1,000 and $2,500 \mathrm{~km}$. respectively.

Variation with distance.-No clear trends are indicated. Comparing the average over the distance ranges $20^{\circ}-40^{\circ}$ and $60^{\circ}-90^{\circ}$ for shallow $(100 \mathrm{~km}$.) shocks, residuals are larger by 0.2 unit for $\mathrm{P}$ in the latter and unchanged for $\mathrm{pP}$. The hypothesis of greater absorption at shallower depths, mentioned above in connection with PP, should produce a distance effect; observed residuals of $\mathrm{P}$ show such an effect, but not of $\mathrm{pP}$. Small variations of $\mathrm{P}$ residuals with distance suggest that the presently accepted velocity distribution with depth should be altered slightly in the direction of steeper slope for depths 880-950, 2,040$2,400 \mathrm{~km}$., and smaller slope for 680-840, 2,440-2,640 km.

Variations with azimuth.-From Pasadena these are small. In shallow shocks a tendency is noted for residuals to be negative in the southwest Pacific and positive in Central and South America.

Variations with region.- Shallow shocks of the Aleutian region show significantly too large $\mathrm{pP}$ energy, by 0.3 unit. The $\mathrm{pP} / \mathrm{P}$ energy ratio is too small by 0.2 in the New Hebrides region and smaller by 0.2 at comparable distance and depth in Japan than in South America. Deep shocks of the southwest Pacific show a smaller $\mathrm{pP} / \mathrm{P}$ ratio than those of South America and Manchuria, but for all except the Aleutian region the separation into $\mathrm{P}$ and $\mathrm{pP}$ is inconclusive and the discrepancy is of the same order as the probable error of the data.

Effect of instruments. - The short-period vertical and horizontal Benioff instruments produce about the same residuals for the same shock. The shortperiod vertical registers larger energy content than the long-period vertical; on the logarithmic scale of energy the difference between the two varies from 0.3 for shocks at $100 \mathrm{~km}$. depth to 0.6 at $600 \mathrm{~km}$. for $P$, with similar results for $\mathrm{pP}$. No effect of distance is indicated for any of the instrumental comparisons.

Wave periods.- The long-period vertical instrument registers larger periods than the short-period vertical, the ratio of periods for the two increasing by wave type in the order $\mathrm{P}, \mathrm{pP}$, and $\mathrm{PP}$ and decreasing with depth. For all depths and instruments the period of $\mathrm{PP}$ is larger than that of $\mathrm{pP}$, and of $\mathrm{pP}$ larger than that of $\mathrm{P}$; this effect is increased with depth of focus and accentuated by the long-period vertical instrument. 


\section{ACKNOWLEDGMENTS}

Dr. B. Gutenberg suggested the research problem and has provided helpful supervision at all stages of the work. Dr. C. F. Richter has been generous with time and suggestions.

Data, calculations, and detailed results are available in the thesis, on file at California Institute of Technology, Pasadena.

California Institute of Teghnology

Pasadena, California

(Division of Geological Sciences, contribution no. 524) 